\title{
Endoscopic Management with a Novel Over-The-Scope Padlock Clip System
}

\author{
Mahesh Kumar Goenka, Gajanan Ashokrao Rodge and Indrajeet Kumar Tiwary \\ Institute of Gastrosciences and Liver, Apollo Gleneagles Hospital, Kolkata, India
}

Background/Aims: The Padlock clip is a recently introduced over-the-scope clip (OTSC) that requires the use of an alternate technique and has a different design from previous OTSCs. However, data regarding its clinical use are limited. The aim of this study is to present our clinical experience using this novel Padlock clip system.

Methods: Between September 2018 and June 2019, 7 consecutive patients underwent Padlock clip application at our center by an experienced endoscopist. A Padlock clip was used for achieving hemostasis in 4 patients presenting with gastrointestinal (GI) bleeding, as well as for endoscopic full-thickness resection in the remaining 3 patients.

Results: All 7 patients achieved technical as well as clinical success, with absence of complications or rebleeding, during a follow-up of a minimum of 3 weeks. All patients were hospitalized post procedure for a minimum of 48 hours, and an absence of adverse events was noted in our patient population throughout the procedure and post-procedure period. Antiplatelet therapy was reinstated shortly after the application of the Padlock clip, with no GI bleeding observed.

Conclusions: The Padlock clip is a novel OTSC, with benefits that include safe, simple, and rapid deployment. Antiplatelet therapy may be reinstated for patients, when necessary, shortly after applying the Padlock clip due to full-thickness closure of the tissue. Clin Endosc 2019;52:574-580

Key Words: Endoscopic management; Gastrointestinal hemorrhages; Novel over-the-scope clip; Over-the-scope clip; Padlock

\section{INTRODUCTION}

Over-the-scope clips (OTSCs) provide a new means of treating gastrointestinal (GI) bleeding and closure of perforations and fistulas. OTSCs from Ovesco (Tübingen, Germany) have been successfully used for both closing GI defects ${ }^{1}$ and in cases of refractory GI bleeding. ${ }^{2}$ OTSC-assisted effective full-thickness resection (EFTR) for removal of mucosal and sub-mucosal GI lesions has also been shown to achieve good

Received: June 23, 2019 Revised: August 27, 2019

Accepted: September 16, 2019

Correspondence: Mahesh Kumar Goenka

Institute of Gastrosciences and Liver, Apollo Gleneagles Hospital, 58 Canal Circular Road, Kadapara, Phool Bagan, Kankurgachi, Kolkata, West Bengal 700054, India

Tel: +91-98-3004-0599, Fax: +91-33-2320-5218, E-mail: mkgkolkata@gmail.com ORCID: https://orcid.org/0000-0003-1700-7543

(c) This is an Open Access article distributed under the terms of the Creative Commons Attribution Non-Commercial License (http://creativecommons.org/ licenses/by-nc/3.0) which permits unrestricted non-commercial use, distribution, and reproduction in any medium, provided the original work is properly cited. results in terms of efficacy and safety. ${ }^{3}$

The Padlock clip (Aponos Medical Co., Kingston, NH, USA) is a more recently introduced device in the category of OTSCs. It requires the use of an alternate technique and has a design that differs from the Ovesco variety of OTSCs. However, data regarding its clinical use are currently limited. ${ }^{4}$ The aim of this study is to present our clinical experience using this novel Padlock clip system.

\section{MATERIALS AND METHODS}

\section{Patient selection}

Seven consecutive patients underwent Padlock clip application at our center between September 2018 and May 2019. The Padlock clip was applied for GI bleeding in 4 patients and for EFTR in 3 patients. All procedures were performed by a senior gastroenterologist at the Institute of Gastrosciences and Liver at our hospital. Informed consent was obtained from all 
the patients after providing a full explanation of the procedure.

\section{Padlock clip system}

The Padlock clip is a 11-mm nitinol ring with 6 needles on the inner aspect pointing towards each other (Fig. 1A). It provides circumferential tissue approximation at $360^{\circ}$ due to its radial compression technology. The prongs lift and approximate the tissue, while tissue controllers assist in limiting the depth of penetration. The spaces between the needles allow blood to flow within the tissue and promotes healing.

The Padlock clip is preassembled in an open position and can be fitted over the tip of the endoscope by using an applicator cap (Fig. 1B). The Padlock clip device is available in two sizes: (1) standard device for endoscopes, with a diameter between 9.5 and $11 \mathrm{~mm}$; (2) Pro-Select device for endoscopes with a diameter between 11.5 and $14 \mathrm{~mm}$. The tissue chamber diameter is fixed at $11 \mathrm{~mm}$ for both the devices; however, the depth of the tissue chamber varies in different devices. The tissue chamber depth is $10 \mathrm{~mm}$ in the standard device, whereas in the Pro-Select device, the depth varies from $8 \mathrm{~mm}$ to $20 \mathrm{~mm}$, depending on the diameter of the scope. The clip is deployed by its lock delivery system, with a trigger wire located parallel to the scope, which is connected to a handle. As soon as the clip is deployed, it regains its original shape due to the high elasticity of the nitinol ring. Effective controlled tissue closure is achieved that can withstand high GI pressures.

\section{Follow-up}

Patient follow-up occurred at 1 and 3 weeks postoperatively. In cases of GI bleeding, technical success was determined at the time of endoscopy by cessation of bleeding, and clinical success was defined in the absence of rebleeding, stable hemoglobin level, and absence of complications. In patients with gastric neuroendocrine tumor (NET) and rectal polyp,

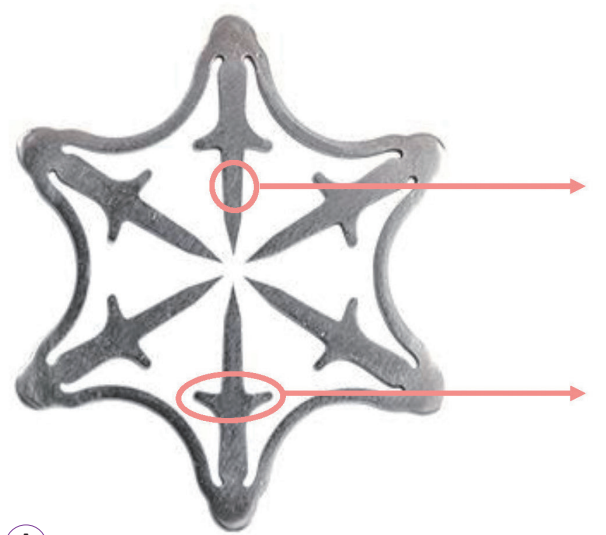

(A)
Prongs lift \& bring the tissue close

Helps in limiting depth of penetration in tissue

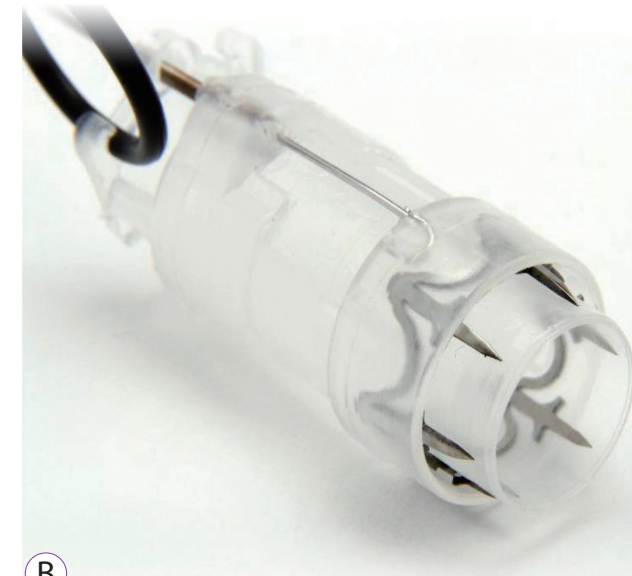

(B)

Fig. 1. (A) Padlock clip (Aponos Medical Co., Kingston, NH, USA) and its parts. (B) Preassembled Padlock clip.

Table 1. Summary of Patient Characteristics

\begin{tabular}{|c|c|c|c|c|c|c|c|c|}
\hline Case No. & Age & Sex & Diagnosis & $\begin{array}{l}\text { Previous thera- } \\
\text { peutic attempt }\end{array}$ & $\begin{array}{l}\text { Primary } \\
\text { success }\end{array}$ & $\begin{array}{l}\text { Follow-up at } \\
1 \text { and } 3 \text { wk }\end{array}$ & $\begin{array}{l}\text { Last follow-up } \\
\text { (days) }\end{array}$ & $\begin{array}{c}\text { Adverse } \\
\text { events }\end{array}$ \\
\hline 1 & 56 & $\mathrm{~F}$ & Angiodysplasia in body of stomach & APC & Yes & No rebleeding & 84 & None \\
\hline 2 & 69 & M & $\begin{array}{l}\text { Large D1 ulcer }(2.5 \mathrm{~cm}) \text { Forrest } \\
\text { class } \mathrm{Ib}\end{array}$ & None & Yes & No rebleeding & 75 & None \\
\hline 3 & 72 & M & $\begin{array}{l}\text { Bleeding gastric ulcer Forrest class } \\
\mathrm{Ib}\end{array}$ & None & Yes & No rebleeding & 70 & None \\
\hline 4 & 49 & M & Gastric NET & None & Yes & No recurrence & 61 & None \\
\hline 5 & 64 & M & $\begin{array}{l}\text { Rectal polyp (Tubular adenoma } \\
\text { with moderate dysplasia) }\end{array}$ & None & Yes & No recurrence & 52 & None \\
\hline 6 & 45 & M & Duodenal NET & None & Yes & No recurrence & 39 & None \\
\hline 7 & 37 & M & $\begin{array}{l}\text { Large D1 ulcer }(2 \mathrm{~cm}) \text { Forrest class } \\
\text { IIa }\end{array}$ & None & Yes & No rebleeding & 21 & None \\
\hline
\end{tabular}

APC, argon plasma coagulation; D1, first part of duodenum; NET, neuroendocrine tumor. 
technical success was determined by the ability to remove the nodule or polyp, and clinical success was based on the absence of recurrence or complications, as well as a stable hemoglobin level throughout the follow-up period.

\section{RESULTS}

A summary of the patients' demographic data, diagnosis, follow-up and adverse events is provided in Table 1. In our study, we used the standard model mounted onto the tip of the gastroscope (Olympus GIF-HQ190, diameter of $9.9 \mathrm{~mm}$, working channel of $2.8 \mathrm{~mm}$; Olympus, Tokyo, Japan). The Padlock clip was applied after invagination of the tissue inside the cap by suction, which also allowed for continuous removal of blood and secretions. Subsequently, after sufficient target tissue could be suctioned into the cap, the clip was deployed creating a pseudo polyp of the target lesion above the closed clip. We did not require any additional auxiliary forceps for tissue invagination.

We used 7 Padlock clips for 4 patient presenting GI bleeding, as well as for 2 patients with NET and 1 patient with rectal polyp. The first patient had 2 different sites of hemorrhage: one site located in the body of the stomach (Fig. 2A) and another located in the first part of duodenum. Hemostasis was not achieved for the stomach lesion after initial use of argon plasma coagulation and drainage was noted on relook endoscopy. This drainage was controlled by application of a Padlock clip at the site of angiodysplasia (Fig. 2B).

The other 2 patients had a duodenal ulcer (Forrest class Ib; Fig. 3A) and gastric ulcer (Forrest class Ib; Fig. 4A), respectively, for which no previous therapeutic intervention had been attempted. Both patients were on dual anticoagulant therapy in the setting of coronary stents, and mechanical options,
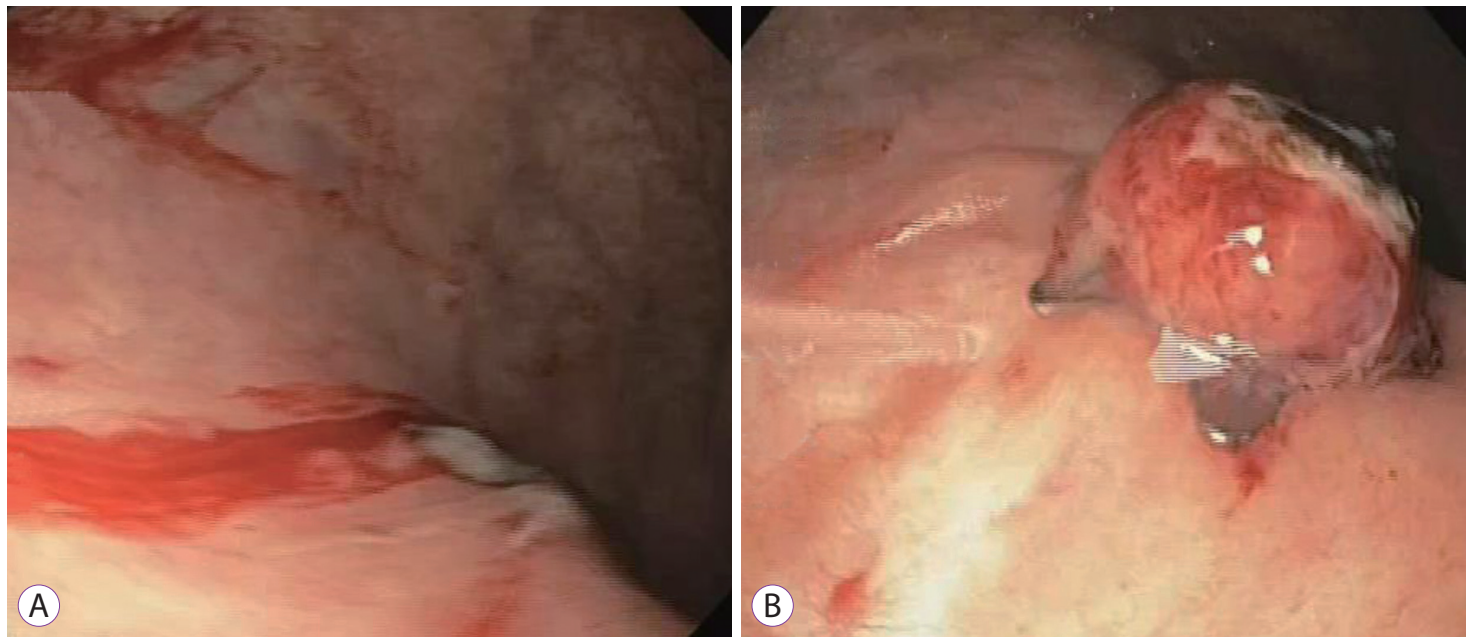

Fig. 2. (A) Angiodysplasia in stomach with discharge. (B) Padlock clip (Aponos Medical Co., Kingston, NH, USA) applied near bleeding point.

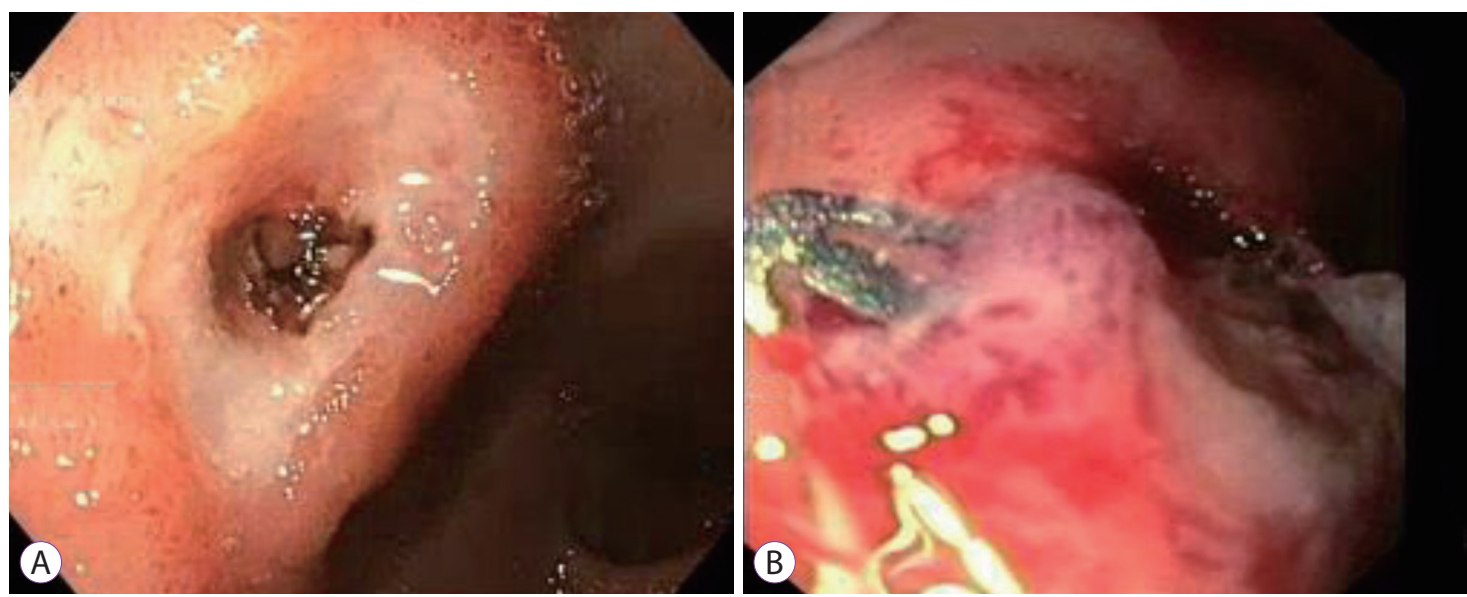

Fig. 3. (A) Large duodenal ulcer observed at first part of duodenum. (B) Padlock clip (Aponos Medical Co., Kingston, NH, USA) applied at the ulcer site. 
rather than thermal options, were preferred. The Padlock clip was successfully deployed in both patients (Figs. 3B, 4B) and hemostasis was achieved. Anticoagulation therapy was reinstated within 48 hours of the endoscopy procedure. The fourth and sixth patients were diagnosed with NETs (Figs. 5A, 6A), while the fifth patient had a sessile rectal polyp (Fig. 7A), with histopathology suggestive of tubular adenoma and moderate dysplasia. The rectal polyp measured $2 \times 2 \mathrm{~cm}$, and the diameter of the gastric and duodenal NET was about $1 \mathrm{~cm}$. A Padlock clip was applied for EFTR of the lesions in these 3 patients (Figs. 5B, 6B, 7B). The lesion was subsequently resected en bloc above the clip using polypectomy snare forceps (Fig. 7B). R0 resection (margins negative for malignancy) was achieved after EFTR of the polyps. There was no noted recurrence of the lesion in the follow-up period at 1 and 3 weeks postoperatively. The seventh patient who presented with hematemesis also had a large ulcer $(2 \mathrm{~cm})$ in the first portion of the duodenum and was managed successfully with Padlock clip application. All 7 patients were hospitalized post procedure for a minimum of 48 hours and were monitored closely for any adverse events.

\section{DISCUSSION}

The currently available endoclips for controlling GI bleeding are either through-the-scope clips or OTSCs. OTSC (Ovesco) has been safely used for closing GI defects and achieving hemostasis, with excellent results. ${ }^{1,2,56}$ The Padlock clip is a novel OTSC that has become popular recently due to
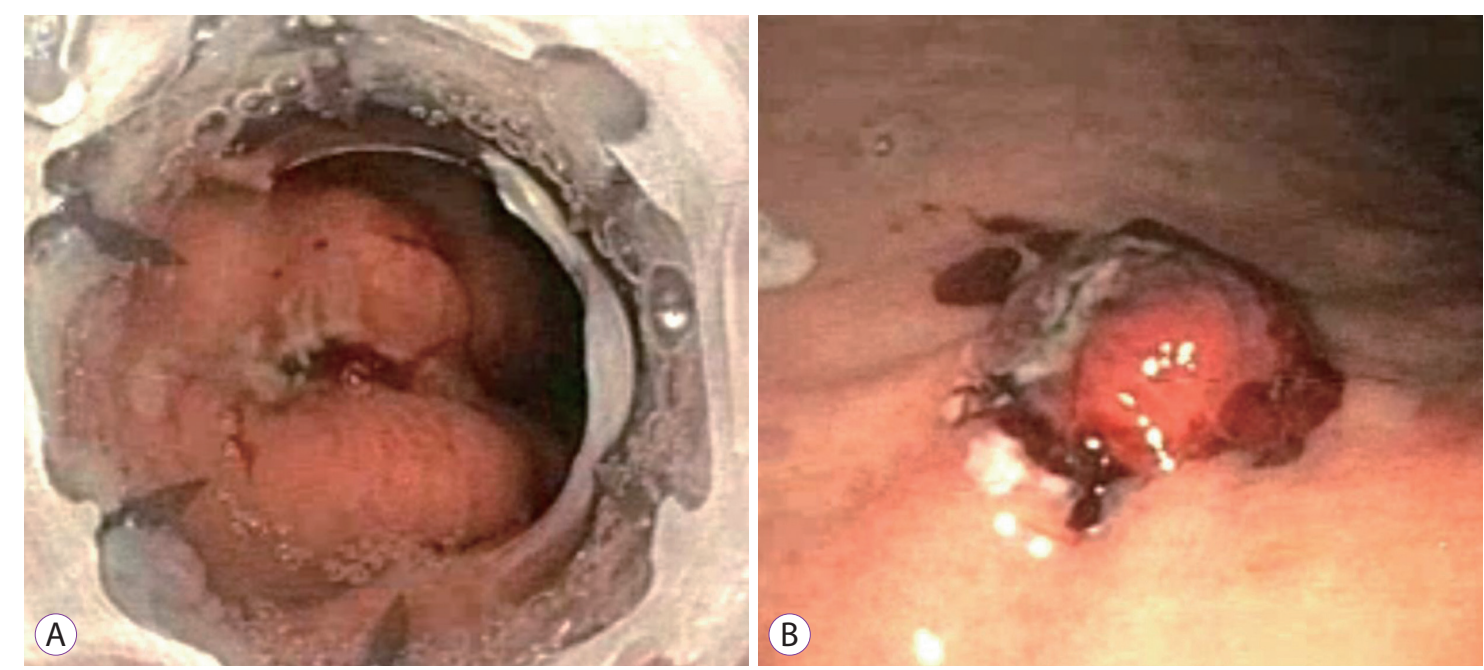

Fig. 4. (A) Discharge from the gastric ulcer. (B) Padlock clip (Aponos Medical Co., Kingston, NH, USA) applied and hemostasis achieved.

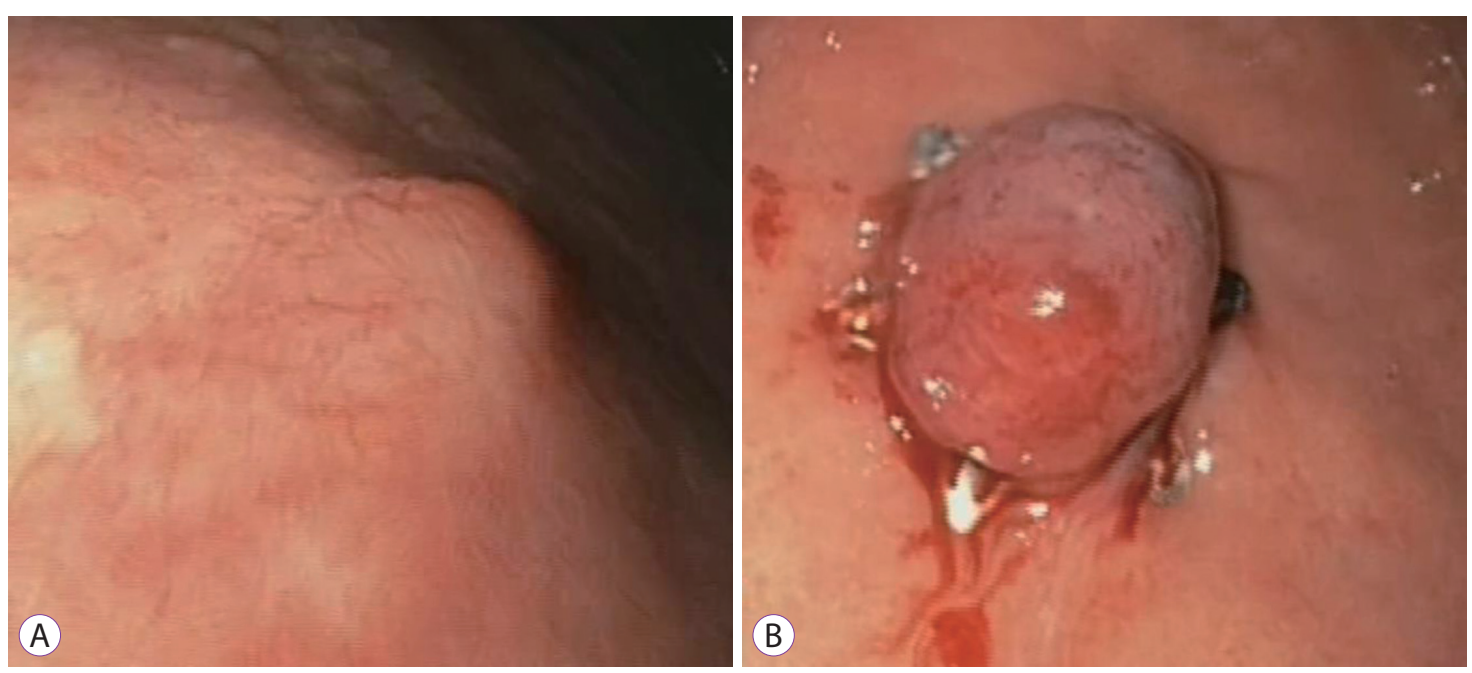

Fig. 5. (A) Gastric neuroendocrine tumor. (B) Padlock clip (Aponos Medical Co., Kingston, NH, USA) surrounding the nodule. 
its unique full-circumferential closing system. The Padlock clip has also been used recently to successfully seal two GI fistulas after using the Ovesco clip. ${ }^{4}$

Although the working mechanism of the Padlock and Ovesco clip systems are similar, they present some important distinctions. The circumferentially-placed inner prongs of the Padlock clip provide a firm grasp to hold the tissue in place and a thorough closure of the area, which is not observed with the Ovesco clip. The Padlock clip system does not require the operating channel of the endoscope, which is occupied when using the Ovesco clip. Major differences between the Ovesco and Padlock clip have been highlighted in Fig. 8 and Table 2.

In the case series published by Dinelli et al., the Padlock clip was used to manage wall defects and GI bleeding in 8 patients, 7 of whom achieved long-term clinical success. ${ }^{4}$ EFTR of colonic lesions was attempted in 6 patients, resulting in full-thickness resection in 50\% of the patients and a deep muscle resection in the remaining 50\% (with R0 resection in $83.3 \%$ of patients).

In another series by Armellini et al. using the Padlock clip, technical success was achieved in all 5 patients: specifically, control of GI bleeding and closure of GI fistula. ${ }^{7}$ Only one adverse event of mild pancreatitis was noted, although its relation to the application of the Padlock clip is questionable.

In the present case series, all patients achieved technical, as well as clinical, success. An absence of adverse events was noted in all patients throughout the procedure and post-procedure period. Hemostasis was achieved in all 4 patients. Patients with gastric ulcer and duodenal ulcer receiving antiplatelet therapy for coronary artery disease had the therapy reinstated shortly after application of the Padlock clip and absence of further GI bleeding was noted. Lamberts et al. has re-

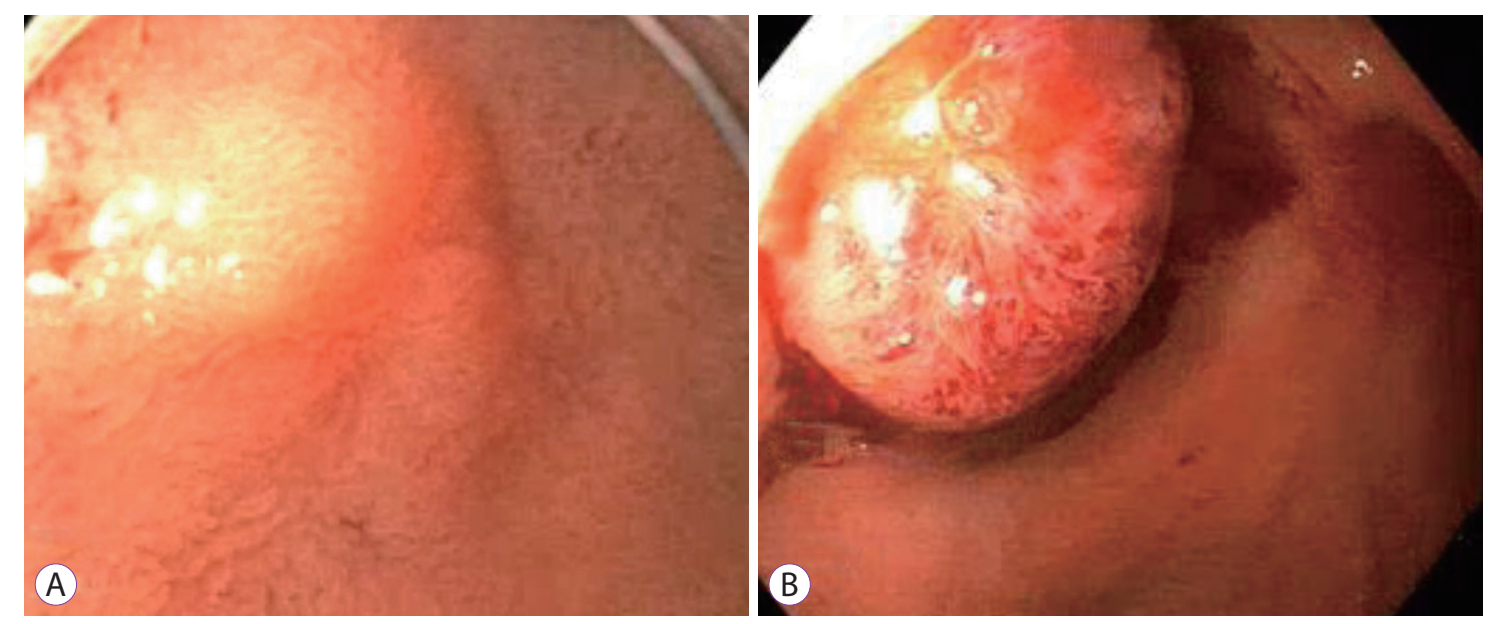

Fig. 6. (A) Duodenal neuroendocrine tumor. (B) Duodenal neuroendocrine tumor after Padlock clip (Aponos Medical Co., Kingston, NH, USA) application.
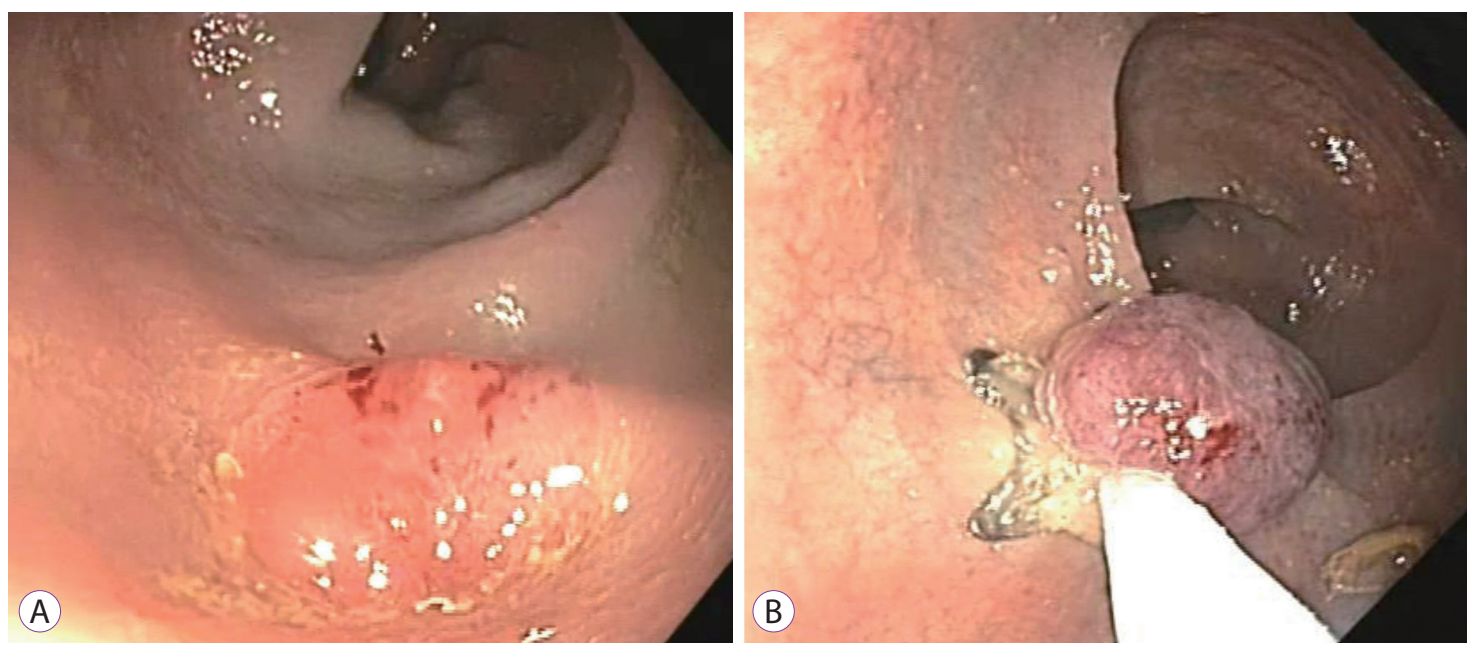

Fig. 7. (A) Rectal Polyp. (B) Padlock clip (Aponos Medical Co., Kingston, NH, USA) surrounding the polyp. 
ported rebleeding in up to $35 \%$ of patients after application of the OTSC. ${ }^{8}$ However, in a larger multicenter study by Manta et al., the premature manifestation of rebleeding was reported in only $4.4 \%$ patients, and there was an absence of rebleeding in the postoperative period. ${ }^{9}$ Rebleeding occurred more frequently in those patients receiving anti-platelet therapy. Inversely, in our previous experience with OTSC, there was an absence of rebleeding after application of the Ovesco clip. ${ }^{5}$ Also, in the present study, there was absence of rebleeding in a follow-up period of a minimum of 3 weeks. Antiplatelet therapy may, therefore, be reinstated shortly after Padlock application due to full thickness closure of the tissue; however, this finding requires further validation in larger studies.

EFTR of the NET and rectal polyp was achieved by Padlock clip application, followed by polypectomy snare removal. Relook endoscopy for all 7 patients revealed the Padlock clip in situ and absence of rebleeding was noted. Padlock clip-assisted EFTR appears to be a safe and effective tool, as well as an alternative to endoscopic mucosal resection, for superficial GI lesions. Nevertheless, complications, such as bleeding, have been reported in $19.2 \%$ patients after endoscopic mucosal resection. ${ }^{10}$ Overall, OTSC-assisted procedures are less complicated and have a shorter learning curve. We chose the OTSC-assisted EFTR because, overall, it is a simple and less time-consuming procedure.

In the only randomized control trial comparing Ovesco with Padlock clips, Prosst et al. performed an ex vivo model experiment that demonstrated that Ovesco consistently halted spurting bleeding; the same could not be said of the Padlock clip. ${ }^{11}$ Nevertheless, all the clinical studies using the Padlock clip for closing GI defects, controlling GI bleeding, and performing EFTR $^{3,4,7,12}$ have demonstrated good results. We have also achieved excellent results in the absence of adverse events in our use of the Padlock clip system. Further randomized clinical trials are needed to compare the efficacy and safety of Padlock versus Ovesco clips.

The limitations of our study are the small sample size and the fact that all procedures were performed by an experienced endoscopist at a specialized center. The disadvantages of the Padlock clip, as well as other OTSCs, include the cost and the
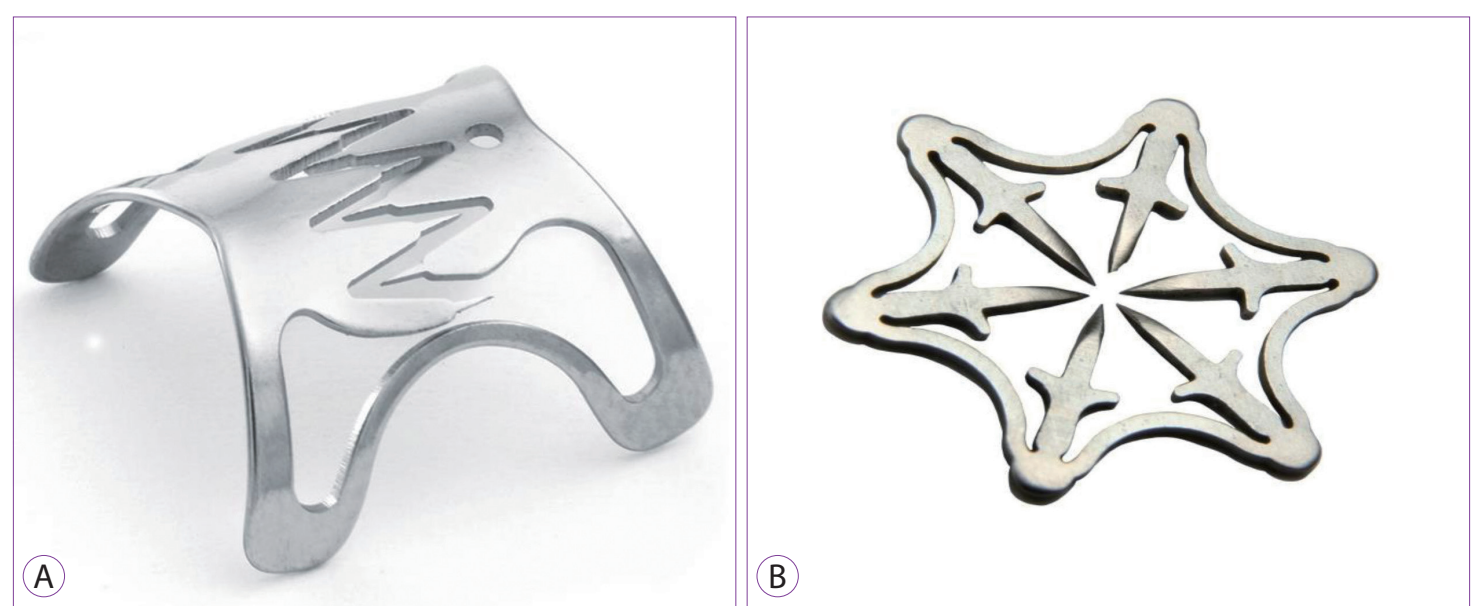

Fig. 8. (A) Ovesco clip (Tübingen, Germany). (B) Padlock clip (Aponos Medical Co., Kingston, NH, USA).

Table 2. Comparison between Ovesco and Padlock Clip

\begin{tabular}{|c|c|}
\hline Ovesco clip & Padlock clip \\
\hline Bear claw-shaped & Hexagonal-shaped \\
\hline Operating channel of endoscope occupied & Operating channel of endoscope is free \\
\hline $\begin{array}{l}\text { Invaginates tissue inside cap by suction or by use of twin } \\
\text { grasper or anchor }\end{array}$ & $\begin{array}{l}\text { Invaginates tissue inside cap only by suction and allows for continuous } \\
\text { removal of blood and secretions }\end{array}$ \\
\hline Absence of circumferential pressure on tissue & $\begin{array}{l}\text { Circumferentially-placed inner prongs create firm hold of tissue and } \\
\text { thorough closure }\end{array}$ \\
\hline Deployed by string wire connected to a rotating handle & Deployed using Lock-it delivery system \\
\hline Remains attached to tissue for a long time (mean, 28 days) ${ }^{6}$ & $\begin{array}{l}\text { May remain attached to tissue for a longer period (documented up to } \\
3 \mathrm{mo})^{7}\end{array}$ \\
\hline
\end{tabular}

Ovesco (Tübingen, Germany), Padlock clip (Aponos Medical Co., Kingston, NH, USA). 
need for reintroduction of the endoscope into the cavity in order to apply the Padlock clip.

In conclusion, the Padlock clip is a novel OTSC with benefits that include a safe, simple, and rapid deployment. It may be an effective tool to seal GI wall defects, achieve hemostasis in refractory GI bleeding, and for EFTR of subepithelial and epithelial lesions. If necessary, antiplatelet therapy may be reinstated shortly after the procedure in patients who underwent successful application of the Padlock clip. Further, large multi-center studies are needed to establish the clinical safety of the Padlock clip and to provide comparison with other conventional techniques.

\section{Conflicts of Interest}

The authors have no financial conflicts of interest.

\section{ORCID}

Gajanan Ashokrao Rodge: https://orcid.org/0000-0002-2417-6110

Indrajeet Kumar Tiwary: https://orcid.org/0000-0003-3883-2366

\section{REFERENCES}

1. Haito-Chavez Y, Law JK, Kratt T, et al. International multicenter experience with an over-the-scope clipping device for endoscopic management of GI defects (with video). Gastrointest Endosc 2014;80:610-622.
2. Manta R, Galloro G, Mangiavillano B, et al. Over-the-scope clip (OTSC) represents an effective endoscopic treatment for acute GI bleeding after failure of conventional techniques. Surg Endosc 2013;27:3162-3164.

3. Fahndrich M, Sandmann M. Endoscopic full-thickness resection for gastrointestinal lesions using the over-the-scope clip system: a case series. Endoscopy 2015;47:76-79.

4. Dinelli M, Omazzi B, Andreozzi P, Zucchini N, Redaelli A, Manes G. First clinical experiences with a novel endoscopic over-the-scope clip system. Endosc Int Open 2017;5:E151-E156.

5. Goenka MK, Rai VK, Goenka U, Tiwary IK. Endoscopic management of gastrointestinal leaks and bleeding with the over-the-scope clip: a prospective study. Clin Endosc 2017;50:58-63.

6. Chan SM, Chiu PW, Teoh AY, Lau JY. Use of the over-the-scope clip for treatment of refractory upper gastrointestinal bleeding: a case series. Endoscopy 2014;46:428-431.

7. Armellini E, Crinò SF, Orsello M, et al. Novel endoscopic over-the-scope clip system. World J Gastroenterol 2015;21:13587-13592.

8. Lamberts R, Koch A, Binner C, et al. Use of over-the-scope clips (OTSC) for hemostasis in gastrointestinal bleeding in patients under antithrombotic therapy. Endosc Int Open 2017;5:E324-E330.

9. Manta R, Mangiafico S, Zullo A, et al. First-line endoscopic treatment with over-the-scope clips in patients with either upper or lower gastrointestinal bleeding: a multicenter study. Endosc Int Open 2018;6:E1317-E1321.

10. Shiba M, Higuchi K, Kadouchi K, et al. Risk factors for bleeding after endoscopic mucosal resection. World J Gastroenterol 2005;11:7335-7339.

11. Prosst RL, Kratt T. A randomized comparative trial of OTSC and Padlock for upper GI hemostasis in a standardized experimental setting. Minim Invasive Ther Allied Technol 2017;26:65-70.

12. Al-Bawardy B, Rajan E, Wong Kee Song LM. Over-the-scope clip-assisted endoscopic full-thickness resection of epithelial and subepithelial GI lesions. Gastrointest Endosc 2017;85:1087-1092. 